\title{
Fleshing out the theory of planned of behavior: Meat consumption as an environmentally significant behavior
}

\author{
Elif Naz Çoker ${ }^{1} \cdot$ Sander van der Linden ${ }^{1}$ (D) \\ Published online: 7 January 2020 \\ (C) The Author(s) 2020
}

\begin{abstract}
The meat industry is a leading cause of climate change in the Western world, and while reducing meat consumption has often been studied as a health behavior, it is equally important to understand its significance as a pro-environmental behavior. In a national sample of the United Kingdom ( $N=737$, Time $1, N=468$, Time 2$)$ we sought to evaluate to what extent the Theory of Planned Behavior (TPB) is an effective model for understanding people's intentions to reduce their meat consumption. Overall, we find that attitudes, subjective norms, and perceived control explain $57 \%$ of the variation in intentions to reduce meat consumption. In turn, past behavior and intention explain $31 \%$ of the variance in self-reported meat consumption behavior four weeks later. Somewhat surprisingly, habit did not have any predictive utility over and above the TPB constructs. The effectiveness of the TPB and implications for devising pro-environmental interventions are discussed.
\end{abstract}

Keywords Pro-environmental behaviors · Theory of planned behavior · Meat consumption

\section{Introduction}

Climate change is continuing to be at the forefront of much scientific and political discussion. Carbon dioxide levels have reached a peak in 2017 that was last seen 3-5 million years ago, while nitrous oxide levels are now at $141 \%$ above preindustrial levels (McGrath 2018). The United Nations Intergovernmental Panel on Climate Change (IPCC 2018) reports that "human activities have [contributed up to] $1.0^{\circ} \mathrm{C}$ of global warming above pre-industrial levels" (p.6), which has already begun to cause changes in land and ocean ecosystems (IPCC 2018). The most recent IPCC report has warned that a warming of $1.5^{\circ} \mathrm{C}$ would cause increased risks of drought,

Electronic supplementary material The online version of this article (https://doi.org/10.1007/s12144-019-00593-3) contains supplementary material, which is available to authorized users.

Sander van der Linden

sander.vanderlinden@psychol.cam.ac.uk

Elif Naz Çoker

enc25@alumni.cam.ac.uk

1 Cambridge Social Decision Making Lab, Department of Psychology, Old Cavendish Laboratory, Free School Lane, University of Cambridge, Cambridge CB2 3RQ, UK floods and extreme heat, resulting in the displacement of communities and leading to economic crises (Watts 2018).

Human activity is a significant contributor to global warming and climate change, both at the individual and societal level (Gardner and Stern 2002; de Groot and Steg 2008; van der Linden et al. 2015). Although it is challenging for individuals to understand the impact of their lifestyle choices and daily consumer behaviors on the environment, these are, in fact, some of the major drivers of climate change (Roy and Pal 2009; Chan and Bishop 2013). Pro-environmental behaviors are complex and challenging to adopt, mainly because they involve simultaneously balancing self-interested versus altruistic motives. In addition, many sustainable behaviors do not have clearly perceivable benefits for the individual and the losses associated with not adopting these behaviors are not solely incurred by the individual but rather shared by the entire population. Moreover, the negative consequences of climate change often seem too "distant in time and place" (Harland et al. 1999, p. 2505; Palomo-Vélez et al. 2018).

There are many green behaviors that have been the focus of social psychological research using the Theory of Planned Behavior (TPB; Ajzen 1985, 1991), such as recycling (Harland et al. 1999; Ramayah et al. 2012; Chan and Bishop 2013), using more public transportation (de Groot and Steg 2007; Hunecke et al. 2001), and saving water and electricity (de Leeuw et al. 2015; Maki and Rothman 2017). While these behaviors are all 
environmentally significant, there is one major contributor to climate change that has arguably received much less attention from social psychological researchers: meat consumption (Zur \& Klockner, 2014; McGrath 2018). Our aim with the current study is to contribute to research that examines reducing meat consumption as an environmentally significant behavior (ESB, as defined by Stern 2000), and to apply the TPB to understand how individuals' intentions and behaviors to eat less meat are shaped by important social psychological factors.

\section{Meat Consumption as an Environmentally Significant Behavior}

The United Nations' Food and Agricultural Organization (FAO) states that meat consumption is responsible for environmental problems such as declining biodiversity, land degradation, atmospheric greenhouse gas emissions, water shortage and pollution (FAO, 2006; Rothgerber 2013; Zur and Klöckner 2014). Global livestock alone accounts for about "12\% of total greenhouse gas emissions" (Westhoek et al. 2011, p. 17), and food industries contribute up to "a third of the total [environmental] impact" in most Western countries (Tukker and Jansen 2006, p. 169).

The globalized adaptation of a Western diet that is high in red and processed meat consumption is one of the main drivers of the increased stress placed by the food industry on the environment. The average global meat consumption in 2014 was about $43 \mathrm{~kg} /$ year per person (Ritchie and Roser 2017), but this number can more than double in some Western countries where meat has become an integral part of the cultural cuisine. For instance, in the Netherlands the population consumes, on average, " $60 \%$ more protein than the recommended daily intake" (de Boer et al. 2014, p.121), and the average North American consumes about $110 \mathrm{~kg}$ of meat yearly, while British consumption is at about $81.5 \mathrm{~kg} /$ year per person (Ritchie and Roser 2017). Currently, about $33 \%$ of the British population consumes more than $100 \mathrm{~g}$ of meat per day (Chalabi 2013). The average amount of consumption of pork meat alone in the UK is $25 \mathrm{~kg} /$ year per person-the same amount that health professionals claim should be our total meat consumption (WWF 2017).

Reducing meat consumption could have significant positive impacts on the environment. A switch to a vegetarian diet from a $100 \mathrm{~g}$ of meat per day intake would lead to about 2.5 times less GHG emissions (Scarborough et al. 2014). Sabaté et al. (2015) report that producing $1 \mathrm{~kg}$ of protein from kidney beans requires " 18 times less land, 10 times less water, and 9 times less fuel" (p.1) than getting the same amount of protein from beef. Stehfest et al. (2009) predict that a worldwide shift to diets low in meat consumption would lower the cost of climate change mitigation by approximately $50 \%$ in 2050 .

\section{The Psychology of Meat Consumption}

Surveying undergraduate students at a North American university, Truelove and Parks (2012) found that participants greatly underestimated the impact of eating meat on global warming and did not seem to recognize the effect of reducing meat consumption in mitigating climate change. In a study ran in rural and urban Scotland, Macdiarmid et al. (2016) have also noted participants' "lack of awareness [about] the association between meat consumption" and the damaging effects of climate change (p.491). Importantly, the participants of this study "showed resistance to the idea of reducing their meat consumption" (p. 490) and expressed skepticism towards the scientific evidence that encouraged them to do so. Similarly, de Boer et al. (2013) found little support for "meat-free" meal campaigns, even among audiences who view climate change as a serious issue. Overall, it appears that people seem to view non-food related ESBs such as recycling and using public transportation as more acceptable while being much less motivated to decrease their meat consumption. Given that problem awareness has been shown to be a significant determinant of attitudes and behavioral intention (Bamberg and Möser 2007; Ramayah et al. 2012), it can be suggested that individuals' ignorance about the links between meat consumption and climate change may be leading them to be less likely to take action to reduce their intake.

However, like most behaviors, meat consumption is also influenced by larger social, economic, and cultural factors as well as various cognitive processes. Although frequently framed as a health issue or a dietary choice, meat consumption is not often portrayed as a moral choice in the context of protecting animal rights and the environment (Bastian et al. 2012). Moreover, meat consumption is not just a food-related decision either as culinary practices are often an important part of culture and even an indicator of social status and identity. For example, traditionally a hard-to-come-by and expensive nutrient, meat is still seen as a symbol of higher income and financial comfort in most societies (Westhoek et al. 2011).

Meat is also a symbol of human domination over nature, associated with the perceived hierarchy of human over animal, as well as male over female (Allen et al. 2000). Consuming the flesh of another animal is often considered to be a symbol of masculinity and power (Allen et al. 2000; Rothgerber 2013; Stibbe, 2004). For instance, Ruby and Heine (2011) report that both female and male participants indicated that they found meat eaters more masculine than their vegetarian counterparts. Indeed, while most males express that a meal is only complete with the presence of meat (Sobal 2005), females often have more negative attitudes toward the use of animals in food and clothing production as well as in scientific and cosmetic experimentation (Rothgerber 2013). In addition to generally being more pro-environmental (Stern et al. 1993), females also experience a reduction in appetite when they are reminded that 
the source of the meat they will consume is a baby animal, while this does not seem to affect males to the same degree (Piazza et al. 2018). It appears from previous research that frequent meat eaters tend to value masculinity, prefer social hierarchy, and view animals as more dissimilar to humans than those who eat less meat or are vegetarians (Loughnan et al. 2014).

Viewing animals as dissimilar to humans is a commonly applied strategy to overcome the cognitive dissonance caused by the so-called 'meat paradox' which occurs when individuals both support animal rights, value their pets, and defend animal welfare, but also express a desire to consume animal products (Loughnan et al. 2014; Bastian et al. 2012; Loughnan et al. (2010). Individuals mentally dissociate the meat they consume from farm animals in an attempt to resolve the cognitive dissonance triggered by the meat paradox (Hoogland et al. 2005). Loughnan et al. (2010) suggest that the "denial of mind and moral status to animals" (p.1) allows us to condone our consumption of them because it implies that animals have a lack of ability to experience and suffer from pain. Two studies have found that when participants are reminded that an animal would be used for food, they were more likely to deny its mental capacities to help reduce their own negative emotions (Loughnan et al. 2010; Bastian et al. 2012).

\section{Theory of Planned Behavior}

Initially developed by Icek Ajzen $(1985,1991)$, the Theory of Planned Behavior (TPB) suggests that our intention to engage in a behavior is influenced by our attitudes (shaped by behavioral beliefs concerning the anticipated outcomes of the behavior and how people evaluate these outcomes), subjective norms (shaped by normative beliefs about others' expectations of the behavior), and perceived behavioral control (PBC, shaped by control beliefs about factors that could facilitate or hinder the performance of the behavior). The theory takes intention as the most proximal determinant of human behavior, depending on the amount of volition and control the individual actually has over the behavior in question. Attitudes are shaped by attributes we associate the behavior with and how positively or negatively we evaluate those attributes. Subjective norms represent social influence; they take into account the normative beliefs of important referent individuals or groups about the behavior. The value we assign to these normative beliefs and our motivation to conform to them determine the strength of subjective norms in predicting behavioral intention. Control beliefs are more complicated, as PBC reflects how many resources and opportunities the individual thinks they possess and how powerful these resources are in the performance of the behavior (Ajzen 1991, 2002, 2006).
Ajzen (2006) argues that if there is enough control over the behavior, then PBC can be used as a proxy for actual control. However, PBC often presents a subjective degree of control and may not be entirely reflective of the actual control an individual has over a certain behavior. $\mathrm{PBC}$ can be interpreted both as self-efficacy in Bandura (1997)'s terms: confidence in one's capability to perform a given behavior under a variety of different circumstances; or as controllability: meaning how much an individual thinks the performance of a particular behavior is up to them. Measuring self-efficacy in the context of $\mathrm{PBC}$ is particularly important because it moderates how much effort an individual puts into seeing the behavior through under challenging circumstances (Godin and Kok 1996).

The role of attitudes, subjective norms, and PBC in predicting intentions and behavior is not uniform but rather "depends on the type of behavior and the nature of the situation" (Ajzen 2002, 2006; Armitage and Conner 2001, p.472). A meta-analysis by Armitage and Conner (2001) shows that, on average, the TPB explains about " $27 \%$ of the variance [in behavior] and about 39\% of the variation in intention" (p. 481). Meta-analytical work examining a wide range of environmentally significant behaviors has found that attitudes, norms, and $\mathrm{PBC}$ are indeed strong predictors of proenvironmental intentions and behaviors (Bamberg and Möser 2007; Maki and Rothman 2017). Following this research, the present study aims to analyze meat consumption as a pro-environmental behavior using TPB constructs and explore the effectiveness of the model.

\section{TPB and Meat Consumption}

Although the TPB has been tested in the context of both meat consumption as a dietary choice and sustainable behavior more generally, to our knowledge, the TPB has not yet been applied to understand meat consumption as a proenvironmental behavior. For example, Saba and di Natale (1998) found that habits were more relevant than the standard TPB constructs in explaining the consumption of red, white, as well as preserved meat in general in an Italian sample. Looking at beef consumption in Ireland, McCarthy et al. (2003) found that attitudes towards beef eating were the strongest predictor of behavior, and that attitudes were in turn influenced by concerns regarding personal health and eating enjoyment but not affected by animal welfare and environmental concerns. Povey et al. (2001) looked at four different diet followers (meat eater, meat avoider, vegetarian and vegan). For each dietary group, the TPB constructs significantly predicted the intention to continue following each diet. Although PBC was the strongest predictor for both vegan and vegetarian diets, subjective norms were not significant for vegetarians. We have not been able to identify any research 
that has specifically looked at the TPB's ability to explain intentions to reduce meat consumption.

\section{Present Study}

Given that the predictive utility of TPB constructs is dependent on the type of behavior, the situational circumstances in which the behavior takes place, and the measurement used for the variables, it is understandable that previous studies looking at meat consumption have found diverging results when it comes to the role of each construct in predicting intention and behavior. The present study expands the existing literature by using the TPB to explain the reduction of meat consumption in the context of pro-environmental behaviors. In addition to measuring attitudes, subjective norms and PBC, the present study also included measures of habit and past behavior. Based on prior literature that has evaluated the TPB, especially in the context of meat consumption and ESBs discussed above, we have formed the following hypotheses for the present study:

$\mathrm{H}_{1}$ : Intention to reduce meat consumption measured in the first wave will be a significant predictor of a reduction in meat consumption behavior measured four weeks later. $\mathrm{H}_{2}$ : Intention to reduce meat consumption will be predicted by attitudes, subjective norms, and the amount of PBC the individual has over reducing meat consumption.

$\mathrm{H}_{3}$ : Meat consumption habits and past behavior will have additional explanatory power over and above the TPB constructs for intentions and behavior.

$\mathrm{H}_{4}$ : There will be gender differences in intention and selfreported meat consumption such that females will be more likely to have both favorable intentions to reduce meat intake as well to report less meat consumption four weeks later.

\section{Method}

\section{Participants and Procedure}

The data for the present study was collected as a part of a twowave study on pro-environmental behaviors. To make clear that this was a study about pro-environmental behavior, the research was advertised to the survey panel as a study about climate change attitudes and behaviors. A national quota sample was recruited from Survey Sampling International (SSI). The sample was representative of gender, age, and region of the population for the United Kingdom. In total, $N=808$ participants completed the first wave of measurements for the TPB constructs, habit and past behavior measures, and $N=501$ answered the second wave questions four weeks later when self-reported behavior was measured, resulting in a 38\% attrition rate. Participants were 50\% male with a modal age bracket of $35-44,53 \%$ had received higher education and $17 \%$ fell into a higher income bracket ( $£ 40,000$ and above). As the main measure of intention and behavior concerned reduction in meat consumption, participants who were already following diets that did not involve meat consumption (e.g. vegetarians) were excluded from the analyses, resulting in 737 valid responses in the first wave and 468 cases in the second wave.

\section{Measures}

Attitudes Participants were asked to rate their attitudes ( $M=$ $3.82, \mathrm{SD}=1.90$ ) towards meat consumption ("Please indicate how you would personally evaluate buying/consuming less meat") on a 7-point bipolar scale ranging from "very unfavorable" to "very favorable". A "non applicable" option was added to exclude participants that already did not consume meat.

Perceived Behavioral Control Participants were asked to rate their perceived self-efficacy $(M=4.32, \mathrm{SD}=1.86)$ on a 7 point scale ranging from "strongly disagree" to "strongly agree" to reduce meat consumption. (e.g. "Considering the next 4 weeks, if I wanted to do so, I firmly believe that I have the ability to buy/consume less meat").

Subjective Norms Participants were asked to rate four statements of subjective normative pressure to help reduce climate change. On a 7-point scale ranging from "strongly disagree" to "strongly agree" ( $M=4.21, \mathrm{SD}=1.46)$, participants were asked about the extent to which it is expected of them to help reduce climate change and what people they value would think about them taking action against climate change. (e.g. "People who are important to me would support me if I decided to change my behavior to help reduce climate change").

Intention Participants were asked to rate their intention to reduce meat consumption $(M=3.57, \mathrm{SD}=2.03)$ in the coming four weeks on a 7-point scale ranging from "very unlikely" to "very likely". A "non-applicable" option was added to exclude participants that already did not consume meat or had other limiting circumstances that affected their meat consumption behavior.

Past Behavior Based on previous literature, the past frequency of performing a behavior was distinguished from behaviors that have become automatic and are performed on a routine basis without conscious thinking. Participants were asked to report the frequency of buying meat while doing groceries $(M=2.87, \mathrm{SD}=1.59)$ on a 7 point bipolar scale ranging from "never" to "all the time". 
Habits Participants were asked to indicate to what extent they think buying meat while groceries has become automatic and whether they perform the behavior without conscious thinking on a routine basis. Defined as such, habit $(M=3.08, \mathrm{SD}=$ 1.82) was measured on a 7-point scale ranging from "strongly disagree" to "strongly agree".

Behavior In the second wave of the study, which took place four weeks after the initial survey, participants were asked to think about the past four weeks and declare the frequency with which they reduced their purchase and consumption of meat $(M=3.38, \mathrm{SD}=1.97)$. This was measured on a 7 -point scale ranging from "not at all" to "very frequently" and with a "non applicable" option if the behavior did not apply to their personal situation. A "non applicable" option was added to exclude participants that already did not consume meat or had other limiting circumstances that affected their meat consumption behavior.

\section{Results}

\section{Exploratory Analyses}

A correlation matrix (Table 1) was created in order to explore the relationships between attitudes, subjective norms, PBC, intentions, behavior, past behavior and habits, and to rule out potential multicollinearity issues between constructs. All variables were significantly and positively correlated with each other at the $p<0.001$ level. The positive correlation coefficients between the TPB constructs suggest that the model could be a good fit for explaining reduced meat consumption. The fairly high positive correlation between past behavior and habit ( $r=$ 0.72 ) showed that these two measures were clearly linked but may capture meat consumption behavior in different ways.

In order to understand the influence of socio-demographic characteristics on the TPB constructs and meat consumption behavior, independent samples $t$-tests were performed.
Education level did not reveal significant differences between participants' responses for any of the measures. There was a significant difference between participants in the high income versus low income bracket (coded as a dummy variable with two groups) but only in measures of past behavior and habits, suggesting that those with higher incomes were more likely to be able to purchase more meat given that it is a relatively expensive food item, but this did not significantly affect their answers to the TPB construct questions. Gender seemed to be the most significant discriminant of TPB constructs (please see Supplementary Tables 1-4 for a detailed overview of $t$ statistics and $p$ values). In line with previous literature, our hypotheses, and the exploratory results demonstrated by the $t$-tests, we decided to only include gender as a demographic variable in the linear regressions for intention and behavior.

\section{Hierarchical Linear Regression Models}

Hierarchical linear regression models were ran to test the predictive utility of demographic characteristics, TPB constructs, and past behaviors and habits on the formation of intentions behaviors to reduce meat consumption. All models and variables were first checked for multicollinearity with VIF statistics (please see Supplementary Tables 3-4). Following van der Linden's (2015) recommendations to estimate hierarchical models with socio-demographic characteristics in the first block, three models were created by adding the theorized psychological variables in each subsequent step to observe changes in explained variance in both intention and self-reported meat consumption. Results are reported in Tables 2 and 3 below with standardized coefficients, significance levels, and adjusted $\mathrm{R}^{2}$ values.

In the first models, gender had a modest but statistically significant contribution to the explained variance for both intention and behavior so that females were more likely than men to reduce their meat consumption $\left(\mathrm{R}^{2}=2 \%\right)$. The significance of gender only remained for behavior across all three models. The TPB constructs (attitude, norms and PBC)
Table 1 Correlation matrix for TPB constructs, past behavior and habit

\begin{tabular}{|c|c|c|c|c|c|c|c|c|}
\hline$N=808$ & 1 & 2 & 3 & 4 & 5 & 6 & Mean & SD \\
\hline 1. Attitudes & & & & & & & 3.82 & 1.90 \\
\hline 2.PBC & $0.51 * * *$ & & & & & & 4.32 & 1.86 \\
\hline 3.Subjective norm & $0.35 * * *$ & $0.27 * * *$ & & & & & 4.21 & 1.46 \\
\hline 4.Intention & $0.69 * * *$ & $0.53 * * *$ & $0.44 * * *$ & & & & 3.57 & 2.03 \\
\hline 5. Behavior & $0.55 * * *$ & $0.34 * * *$ & $0.32 * * *$ & $0.53 * * *$ & & & 3.38 & 1.97 \\
\hline 6. Past behavior & $0.47 * * *$ & $0.20 * * *$ & $0.13 * * *$ & $0.40 * * *$ & $0.33 * * *$ & & 2.87 & 1.59 \\
\hline 7. Habit & $0.32 * * *$ & $0.21 * * *$ & $0.11 * * *$ & $0.31 * * *$ & $0.21 * * *$ & $0.71 * * *$ & 3.08 & 1.82 \\
\hline
\end{tabular}

$* p<0.05, * * p<0.01, * * * p<0.001$. All variables are coded so that higher values reflect greater endorsement of the items. For $r$-values, the absolute value is the effect size (Cohen 1992) 
Table 2 Hierarchical linear regression models for intention

\begin{tabular}{llll}
\hline $\begin{array}{l}\text { Independent } \\
\text { variables }\end{array}$ & $\begin{array}{l}\text { Socio-demographics Model } \\
1(\beta)\end{array}$ & $\begin{array}{l}\text { TPB constructs Model 2 } \\
(\beta)\end{array}$ & $\begin{array}{l}\text { Past behavior habit Model 3 } \\
(\beta)\end{array}$ \\
\hline Gender & $0.13^{* * *}$ & 0.04 & 0.05 \\
Attitude & - & $0.52^{* * *}$ & $0.46^{* * *}$ \\
Subjective norms & - & $0.18^{* * * *}$ & $0.19^{* * *}$ \\
PBC & - & $0.22^{* * * *}$ & $0.21^{* * *}$ \\
Past behavior & - & - & $0.11^{* *}$ \\
Habit & - & - & 0.02 \\
$\mathrm{~N}$ & 737 & 728 & 728 \\
Adj. $\mathrm{R}^{2}$ & 0.02 & 0.56 & 0.57 \\
$\Delta$ adj. & & 0.54 & 0.01 \\
$\mathrm{~F}_{\text {change }}$ & 13.69 & 298.461 & 9.93 \\
$* p<0.05, * * p<0.01, * * * p<0.001$ & &
\end{tabular}

entered in Model 2 all significantly contributed to the explained variance for intention and resulted in a significant and large increase in the adjusted $R^{2}$ value $\left(\Delta R^{2}=54 \%\right)$, demonstrating that TPB constructs - and especially attitudes $(\beta=0.52)$ - were the best predictors over and above gender for intentions to reduce meat consumption. In the second model predicting behavior, intention had the highest statistically significant contribution to the explained variance $\left(\Delta \mathrm{R}^{2}=\right.$ $27 \%)$, whilst PBC was not a significant predictor $(p=0.06)$. $\mathrm{PBC}$ was entered into the regression equation as a proxy for actual control. Its lack of significance may indicate that for reducing meat consumption as an $\mathrm{ESB}, \mathrm{PBC}$ may not be an accurate proxy for actual behavioral control. In Model 3 , past behavior (measuring the frequency of purchase and consumption of meat) had a small but significant contribution for both intention and behavior, whereas habit measures, capturing the automated and routine nature of performing the behavior, did not. Overall, the final TPB models accounted for about $\mathrm{R}^{2}=57 \%$ of the variance in intentions to reduce meat consumption and $\mathrm{R}^{2}=31 \%$ of the variance in self-reported behavior.

\section{Discussion}

The present study looked at the reduction of meat consumption as a pro-environmental behavior, using the TPB constructs to understand intentions and self-reported behavioral patterns of purchasing less meat. In addition to attitudes, subjective norms, and PBC - the three components of TPB that contribute to the formation of intentions - we also looked at gender as well as past behaviors and habit formation related to meat consumption using online surveys administered in two waves that were four weeks apart in a national sample of the UK population. We used hierarchical linear regression models to analyze the contribution of the TPB constructs, gender, past behavior, and habits on intentions and self-reported reductions of meat consumption. In line with prior literature on proenvironmental behaviors, we found that all of the TPB constructs significantly predicted intentions and behavior. However, unlike previous research on meat consumption as a dietary choice, meat consumption habits did not significantly associate with self-reported reductions in meat consumption.
Table 3 Hierarchical linear regression models for behavior

\begin{tabular}{llll}
\hline $\begin{array}{l}\text { Independent } \\
\text { variables }\end{array}$ & $\begin{array}{l}\text { Socio-demographics Model } \\
1(\beta)\end{array}$ & $\begin{array}{l}\text { TPB constructs Model 2 } \\
(\beta)\end{array}$ & $\begin{array}{l}\text { Past behavior habit Model 3 } \\
(\beta)\end{array}$ \\
\hline Gender & $0.17^{* * *}$ & $0.12^{* *}$ & $0.12^{* * *}$ \\
Intention & - & $0.47^{* * *}$ & $0.41^{* * *}$ \\
PBC & - & 0.09 & 0.09 \\
Past behavior & - & - & $0.16^{* *}$ \\
Habit & - & - & -0.04 \\
N & 468 & 437 & 437 \\
Adj. $\mathrm{R}^{2}$ & 0.03 & 0.30 & 0.31 \\
$\Delta$ adj. & & 0.27 & 0.01 \\
Fchange & 14.51 & 81.91 & 5.29 \\
\hline
\end{tabular}

$* p<0.05, * * p<0.01, * * * p<0.001$ 


\section{Hypotheses}

We found mixed evidence relating to our four hypotheses but overall our results demonstrate that the TPB is a good model for explaining reductions in meat consumption as a pro-environmental behavior. $\mathrm{H}_{1}$ was supported as the linear regressions demonstrated that intention to limit meat consumption was the strongest significant predictor of behavior, over and above gender, past behavior, and habit. Overall, intention, $\mathrm{PBC}$, and past behavior accounted for about $30 \%$ of the explained variance in self-reported behavior, which is consistent with the average reported in meta-analyses (Armitage and Conner 2001). $\mathrm{H}_{2}$ was also supported as the variance in intention was explained by attitudes, subjective norms and $\mathrm{PBC}$ over and above gender, past behavior, and habit. These three factors together explained $54 \%$ of the variance, in line with metaanalytical averages. Attitudes were found to be the strongest predictors of intention out of the three TPB constructs, once again in line with findings reported in the same meta-analysis. The low contribution of subjective norms in our models could be due to the fact that most individuals do not feel a lot of external pressure to engage in pro-environmental behaviors that can help limit climate change (or meat consumption). Interestingly, $\mathrm{H}_{3}$ was partially supported such that past behaviors did have a meaningful and statistically significant contribution to explained variance in both intentions and behavior, but habits did not. This contradicts previous literature on meat consumption as a dietary behavior where habits have had explanatory power over and above TPB constructs (Saba and Di Natale 1998). However, it is important to note that previous literature had meat consumption as the outcome behavior, while we have measured reductions in meat consumption. Changing a behavior implies resistance to automated routines, and a stronger exercise of self-control, motivated by personal and social norms. This might explain why attitudes, subjective norms, and PBC can help overcome the effect of habits when it comes to eating less meat. $\mathrm{H}_{4}$ was partially supported for self-reported behavior as gender differences significantly contributed to the explained variance in behavior in each model; even after TPB constructs, past behavior and habits were entered in the regression. This is in line with prior research which has found that gender was a predictor of vegetarianism (Gossard and York 2003), that females were more likely to think about the links between their actions and the environment (Stern et al. 1993), and that females were less approving of use of animals for food production (Rothgerber 2013). $\mathrm{H}_{4}$ was not supported for intentions, given that although gender had a significant coefficient in Model 1, this did not persist when TPB factors were accounted for.

\section{TPB}

The Theory of Planned Behavior has shown to be an effective model for explaining behaviors across domains ranging from health and dietary choices to pro-environmental actions. Previous literature has found that the TPB has been particularly a good model for explaining pro-environmental behaviors (Bamberg and Möser 2007; Maki and Rothman 2017). As the current research aimed to study reductions in meat consumption in the context of mitigating climate change, we have chosen to adapt the TPB to this particular behavior. We have measured attitudes, subjective norms, PBC, intention and selfreported behavior in accordance with previous studies. In proenvironmental behavior research, subjective norms have often been noted as the most problematic construct of the TPB, often being criticized for not fully capturing the social pressures an individual might experience regarding a behavior (Armitage and Conner 2001; van der Linden 2011). A lack of valid and reliable measures, the misidentification of a relevant referent group, and the conditions surrounding the behavior could all contribute to subjective norms failing to capture the influence of social referents' evaluations of a behavior on the individual. We have tried to address this problem by measuring subjective norms related to mitigating climate change using four items that measured expectations, support, and opinions of valued others. Dietary choices in isolation may seem like personal choices that have little to do with social acceptance, but once framed as a behavior that helps tackle climate change, reducing meat consumption gains a socially relevant context.

While subjective norms significantly predicted intentions to reduce meat consumption, attitudes were the strongest contributor. Attitudes are a culmination of behavioral beliefs that are composed of individuals' evaluations of the potential outcomes of the behavior. This may help explain why attitudes shaped by personal convictions about the potential outcomes of reducing meat consumption would have the largest influence on intentions. This would also be in line with findings which demonstrate that problem awareness indirectly contributes to intentions by shaping attitudes (Bamberg and Möser 2007; Ramayah et al. 2012). Based on our findings, we can suggest that increasing knowledge about the environmental benefits of reducing meat consumption may be effective in changing attitudes and increasing intentions to eat less meat.

Interestingly, $\mathrm{PBC}$ was found to be the weakest contributor compared to attitudes and subjective norms for intentions and did not significantly predict behavior. Ajzen (2006) has suggested that PBC should be entered to the TPB model as a factor influencing both intention and actual behavior because it can be used as a proxy for actual volitional control over the behavior. However, the non-significant effect of PBC in predicting behavior in our study might suggest that in the context of reducing meat consumption to help tackle climate change, PBC may not 
be an accurate proxy for actual control. Keeping up with dietary restrictions is dependent on multiple factors including the availability of alternatives, cost-benefit calculations, as well as social and cultural circumstances. Individuals' perception of the control they have over the behavior may not be completely accurate when it comes to actually reducing their meat consumption due to these confounding factors.

\section{Implications}

The present study provides initial evidence that the TPB is a suitable model for explaining the reduction of meat consumption as an ESB, with $57 \%$ and $31 \%$ of the variance explained in intentions and behavior, respectively. Previous research which has studied meat consumption as a dietary choice has shown that habits were better predictors of intention and behavior over and above TPB constructs (Saba and Di Natale 1998). Our results somewhat contradict this, demonstrating that although past behavior (but not habit) was a significant predictor of intention and behavior, attitudes, subjective norms, and PBC explained much more variance in reducing meat consumption.

Notably, attitudes were the strongest predictor of intentions, suggesting that the accessible beliefs an individual has about reducing meat consumption and the affective value of its potential outcomes, could be more influential than their perception of referent groups and individuals' behavioral expectations as well as their own perceived control over the said behavior. Environmental activists, policymakers, nongovernmental organizations that want to encourage the larger public to reduce their meat consumption could benefit from targeting these behavioral beliefs, trying to increase awareness about the environmental impact of the meat industry, and how individual reductions in meat intake can have significant contributions to mitigating climate change.

Gender differences have persisted in the regression models for behavior, even after TPB constructs, past behavior and habits were entered, such that females were likely to reduce their meat consumption more than males. This finding is in line with previous literature on meat consumption and gender differences discussed above which has shown that females are more likely to express negative feelings about consuming animals and more likely to respond to cues that reduce appetite for meat eating (Rothgerber 2013; Piazza et al. 2018). Pairwise comparisons suggest that females may have more salient behavioral beliefs about the positive outcomes of reducing meat consumption than males. Females also reported to have higher levels of PBC and seemed to think that their referent groups were more alarmed about climate change and expected them to engage in behaviors that tackled climate change more than males did. Future research can explore why males are less likely to think they have behavioral control over reducing their meat consumption, as well as why they are more likely to believe their social referent groups and individuals are less expectant or supportive of ESBs. If these questions are answered, interventions can be tailored specifically for males who hold strong views about the association between meat eating and masculinity.

This study is one of few that has examined the reduction of meat consumption as a pro-environmental behavior and assessed the explanatory power of the TPB within this context. Future research can expand the findings of this study by including objective measures of behavior (e.g. see Garnett et al. 2019), repeating the study in different cultural contexts, and exploring the moderating role of individuals' awareness of the link between meat consumption and global warming. While these results have mainly served a diagnostic purpose in understanding some of the socio-cognitive factors guiding intention and behaviors related to the reduction of meat consumption, they could be used to inform strategies for interventions that will encourage individuals to adapt a diet that is lower on meat intake in order to help mitigate the negative consequences of climate change.

\section{Limitations}

Of course, this study is not without limitations. First, although longitudinal data provide greater confidence in estimating potential causal relationships, the results remain correlational and are based on a single study and the conclusions should therefore be interpreted within the context of a non-experimental design. Second, another important limitations of this study was the fact that many constructs were measured with a single item. This may have introduced some measurement error in the TPB constructs and prevented a latent variable (SEM) approach. A third limitation was that although we have included a "not applicable" option for the majority of the items, we have not clearly distinguished between meat eaters, vegetarians, or people who follow other dietary habits that limit or change their meat consumption. Lastly, we have relied on self-reports of meat consumption rather than observed behavior. Previous TPB metaanalyses have underlined that the explanatory power of the model decreases when behavior is observed objectively rather than self-reported (Armitage and Conner 2001). Future (experimental) research could change behavior directly by manipulating the choice environment (Garnett et al. 2019) or include both self-reported and more objective (e.g. observed) measures of reductions in meat consumption over time.

\section{Conclusion}

This study aimed to bridge the gap between social psychological research that has applied TPB to pro-environmental behaviors and to meat consumption as a dietary choice and health behavior. Rising public awareness about the significant negative impact that the global meat industry has on the 
environment makes this study particularly relevant. Since the participants of the study were part of a national sample of the UK, our results can help inform future research and suggestions for interventions in the UK. Unlike most TPB research that has relied on a cross-sectional design, we asked our participants to report their reduction in meat consumption four weeks following the initial wave of the survey, thus increasing the validity of our behavioral outcome measures.

The findings of the study show that the TPB model explains a fairly substantial amount of variation in both intentions and selfreported reductions in meat consumption, with $\mathrm{R}^{2}$ values slightly above averages reported in previous meta-analyses. Future research can further explore the importance of attitudes in forming intentions to reduce meat consumption and test its usefulness as a tool for planning future interventions. Raising awareness about greenhouse gas emissions caused by the meat industry and the positive impacts a vegetarian diet could have on the environment could all be effective ways for changing behavioral beliefs about personal meat consumption.

Moreover, although habit has predicted meat consumption in dietary choice studies, our findings show that previous automatic behaviors related to meat purchase and consumption did not hinder the formation of intentions to reduce said behavior. Perhaps reminding individuals that meat consumption is not just a personal dietary choice but also an ESB led to more salient beliefs about the potential positive outcomes of reducing meat intake despite previously formed habits. Finally, the small but significant gender difference in meat consumption behavior is worth noting. Changing the perceptions of meat as the only source of protein that is necessary for a healthy body, and dissociating it from being a symbol of hierarchy and supremacy may be important for encouraging males to develop more positive behavioral and normative beliefs about reducing meat consumption.

\section{Compliance with Ethical Standards}

Ethical Approval All procedures performed in studies involving human participants were in accordance with the ethical standards of the institutional and/or national research committee (Cambridge Department of Psychology Ethics Committee 2018/19-37) and with the 1964 Helsinki declaration and its later amendments or comparable ethical standards.

Conflict of Interest On behalf of all authors, the corresponding author states that there is no conflict of interest, financial or otherwise.

Open Access This article is licensed under a Creative Commons Attribution 4.0 International License, which permits use, sharing, adaptation, distribution and reproduction in any medium or format, as long as you give appropriate credit to the original author(s) and the source, provide a link to the Creative Commons licence, and indicate if changes were made. The images or other third party material in this article are included in the article's Creative Commons licence, unless indicated otherwise in a credit line to the material. If material is not included in the article's Creative Commons licence and your intended use is not permitted by statutory regulation or exceeds the permitted use, you will need to obtain permission directly from the copyright holder. To view a copy of this licence, visit http://creativecommons.org/licenses/by/4.0/.

\section{References}

Ajzen, I. (1985). From intentions to actions: A theory of planned behavior. In J. Kuhl et al. (Eds.), Action control (pp. 11-39). Berlin, Heidelberg: Springer.

Ajzen, I. (1991). The theory of planned behavior. Organizational Behavior and Human Decision Processes, 50(2), 179-211.

Ajzen, I. (2002). Perceived behavioral control, self-efficacy, locus of control, and the theory of planned behavior. Journal of Applied Social Psychology, 32(4), 665-683.

Ajzen, I. (2006). Behavioral interventions based on the theory of planned behavior. Retrieved from: https://people.umass.edu/aizen/pdf/tpb. intervention.pdf

Allen, M. W., Wilson, M., Ng, S. H., \& Dunne, M. (2000). Values and beliefs of vegetarians and omnivores. The Journal of Social Psychology, 140(4), 405-422.

Armitage, C. J., \& Conner, M. (2001). Efficacy of the theory of planned behaviour: A meta-analytic review. British Journal of Social Psychology, 40(4), 471-499.

Bamberg, S., \& Möser, G. (2007). Twenty years after Hines, Hungerford, and Tomera: A new meta-analysis of psycho-social determinants of pro-environmental behaviour. Journal of Environmental Psychology, 27(1), 14-25.

Bandura, A., \& Wessels, S. (1997). Self-efficacy: The exercise of control. New York: Freeman.

Bastian, B., Loughnan, S., Haslam, N., \& Radke, H. R. (2012). Don't mind meat? The denial of mind to animals used for human consumption. Personality and Social Psychology Bulletin, 38(2), 247-256.

Chalabi, M. (2013). Comparing carnivores: UK meat consumption. The Guardian. Retrieved from https://www.theguardian.com/news/ datablog/2013/jun/05/meat-consumption-uk-global-trends

Chan, L., \& Bishop, B. (2013). A moral basis for recycling: Extending the theory of planned behaviour. Journal of Environmental Psychology, 36, 96-102.

Cohen, J. (1992). A power primer. Psychological Bulletin, 112(1), 155-159.

de Boer, J., Schösler, H., \& Boersema, J. J. (2013). Climate change and meat eating: An inconvenient couple? Journal of Environmental Psychology, 33, 1-8.

de Boer, J., Schösler, H., \& Aiking, H. (2014). "Meatless days" or "less but better"? Exploring strategies to adapt Western meat consumption to health and sustainability challenges. Appetite, 76, 120-128.

de Groot, J. I., \& Steg, L. (2007). Value orientations and environmental beliefs in five countries: Validity of an instrument to measure egoistic, altruistic and biospheric value orientations. Journal of CrossCultural Psychology, 38(3), 318-332.

de Groot, J. I., \& Steg, L. (2008). Value orientations to explain beliefs related to environmental significant behavior: How to measure egoistic, altruistic, and biospheric value orientations. Environment and Behavior, 40(3), 330-354.

de Leeuw, A., Valois, P., Ajzen, I., \& Schmidt, P. (2015). Using the theory of planned behavior to identify key beliefs underlying proenvironmental behavior in high-school students: Implications for educational interventions. Journal of Environmental Psychology, $42,128-138$.

FAO, Food and Agriculture Organization, UN. (2006), "Livestock's Long Shadow: Environmental Issues and Options", United Nations Food and Agriculture Organization, Rome. Retrieved from: http://www.fao.org/3/a-a0701e.pdf

Gardner, G. T., \& Stern, P. C. (2002). Environmental problems and human behavior ( $2 \mathrm{nd}$ ed.). Boston: Pearson Custom Publishing. 
Garnett, E. E., Balmford, A., Sandbrook, C., Pilling, M. A., \& Marteau, T. M. (2019). Impact of increasing vegetarian availability on meal selection and sales in cafeterias. Proceedings of the National Academy of Sciences, 116(42), 20923-20929.

Godin, G., \& Kok, G. (1996). The theory of planned behavior: A review of its applications to health-related behaviors. American Journal of Health Promotion, 11(2), 87-98.

Gossard, M. H., \& York, R. (2003). Social structural influences on meat consumption. Human Ecology Review, 10(1), 1-9.

Harland, P., Staats, H., \& Wilke, H. A. (1999). Explaining proenvironmental intention and behavior by personal norms and the theory of planned behavior. Journal of Applied Social Psychology, 29(12), 2505-2528.

Hoogland, C. T., de Boer, J., \& Boersema, J. J. (2005). Transparency of the meat chain in the light of food culture and history. Appetite, 45(1), 15-23.

Hunecke, M., Blöbaum, A., Matthies, E., \& Höger, R. (2001). Responsibility and environment: Ecological norm orientation and external factors in the domain of travel mode choice behavior. Environment and Behavior, 33(6), 830-852.

Intergovernmental Panel for Climate Change. (2018). Global warming of $1.5{ }^{\circ} \mathrm{C}$ : Summary for policymakers. https://www.ipcc.ch/sr15/ chapter/summary-for-policy-makers/.

Loughnan, S., Haslam, N., \& Bastian, B. (2010). The role of meat consumption in the denial of moral status and mind to meat animals. Appetite, 55(1), 156-159.

Loughnan, S., Bastian, B., \& Haslam, N. (2014). The psychology of eating animals. Current Directions in Psychological Science, 23(2), 104-108.

Macdiarmid, J. I., Douglas, F., \& Campbell, J. (2016). Eating like there's no tomorrow: Public awareness of the environmental impact of food and reluctance to eat less meat as part of a sustainable diet. Appetite, 96, 487-493.

Maki, A., \& Rothman, A. J. (2017). Understanding pro-environmental intentions and behaviors: The importance of considering both the behavior setting and the type of behavior. The Journal of Social Psychology, 157(5), 517-531.

McCarthy, M., de Boer, M., O'Reilly, S., \& Cotter, L. (2003). Factors influencing intention to purchase beef in the Irish market. Meat Science, 65(3), 1071-1083.

McGrath, M. (2018). Climate change: Warming gas concentrations at new record high. $B B C$ news, Retrieved from https://www.bbc.co.uk/.

Palomo-Vélez, G., Tybur, J. M., \& van Vugt, M. (2018). Unsustainable, unhealthy, or disgusting? Comparing different persuasive messages against meat consumption. Journal of Environmental Psychology, $58,63-71$.

Piazza, J., McLatchie, N., \& Olesen, C. (2018). Are baby animals less appetizing? Tenderness toward baby animals and appetite for meat. Anthrozoös, 31(3), 319-335.

Povey, R., Wellens, B., \& Conner, M. (2001). Attitudes towards following meat, vegetarian and vegan diets: An examination of the role of ambivalence. Appetite, 37(1), 15-26.

Ramayah, T., Lee, J. W. C., \& Lim, S. (2012). Sustaining the environment through recycling: An empirical study. Journal of Environmental Management, 102, 141-147.

Ritchie, H., \& Roser, M. (2017). Meat and Seafood Production \& Consumption. Our World in Data, https://ourworldindata.org/

Rothgerber, H. (2013). Real men don't eat (vegetable) quiche: Masculinity and the justification of meat consumption. Psychology of Men \& Masculinity, 14(4), 363.
Roy, J., \& Pal, S. (2009). Lifestyles and climate change: Link awaiting activation. Current Opinion in Environmental Sustainability, 1(2), 192-200.

Ruby, M. B., \& Heine, S. J. (2011). Meat, morals, and masculinity. Appetite, 56(2), 447-450.

Saba, A., \& Di Natale, R. (1998). A study on the mediating role of intention in the impact of habit and attitude on meat consumption. Food Quality and Preference, 10(1), 69-77.

Sabaté, J., Sranacharoenpong, K., Harwatt, H., Wien, M., \& Soret, S. (2015). The environmental cost of protein food choices. Public Health Nutrition, 18(11), 2067-2073.

Scarborough, P., Appleby, P. N., Mizdrak, A., Briggs, A. D., Travis, R. C., Bradbury, K. E., \& Key, T. J. (2014). Dietary greenhouse gas emissions of meat-eaters, fish-eaters, vegetarians and vegans in the UK. Climatic Change, 125(2), 179-192.

Sobal, J. (2005). Men, meat, and marriage: Models of masculinity. Food and Foodways, 13(1-2), 135-158.

Stehfest, E., Bouwman, L., Van Vuuren, D. P., Den Elzen, M. G., Eickhout, B., \& Kabat, P. (2009). Climate benefits of changing diet. Climatic Change, 95(1-2), 83-102.

Stern, P. C. (2000). New environmental theories: Toward a coherent theory of environmentally significant behavior. Journal of Social Issues, 56(3), 407-424.

Stern, P. C., Dietz, T., \& Kalof, L. (1993). Value orientations, gender, and environmental concern. Environment and Behavior, 25(5), 322-348.

Stibbe, A. (2004). Health and the social construction of masculinity in Men's Health magazine. Men and Masculinities, 7(1), 31-51.

Truelove, H. B., \& Parks, C. (2012). Perceptions of behaviors that cause and mitigate global warming and intentions to perform these behaviors. Journal of Environmental Psychology, 32(3), 246-259.

Tukker, A., \& Jansen, B. (2006). Environmental impacts of products: A detailed review of studies. Journal of Industrial Ecology, 10(3), 159-182.

van der Linden, S. (2011). Charitable intent: A moral or social construct? A revised theory of planned behavior model. Current Psychology, 30(4), 355-374.

van der Linden, S. (2015). The social-psychological determinants of climate change risk perceptions: Towards a comprehensive model. Journal of Environmental Psychology, 41, 112-124.

Van der Linden, S., Maibach, E., \& Leiserowitz, A. (2015). Improving public engagement with climate change: Five "best practice" insights from psychological science. Perspectives on Psychological Science, 10(6), 758-763.

Watts, J. (2018). We have 12 years to limit climate change catastrophe, warns UN. The Guardian, Retrieved from https://www.theguardian. com/environment/2018/oct/08/global-warming-must-not-exceed$15 \mathrm{c}$-warns-landmark-un-report

Westhoek, H., Rood, T., van den Berg, M., Janse, J., Nijdam, D., Reudink, M., \& Woltjer, G. B. (2011). The protein puzzle: the consumption and production of meat, dairy and fish in the European Union (No. 500166001). Netherlands Environmental Assessment Agency.

World Wildlife Foundation (WWF). (2017). Appetite for Destruction. Retrieved from https://www.wwf.org.uk/updates/appetite-fordestruction

Zur, I., \& Klöckner, C. A. (2014). Individual motivations for limiting meat consumption. British Food Journal, 116(4), 629-642.

Publisher's Note Springer Nature remains neutral with regard to jurisdictional claims in published maps and institutional affiliations. 